\title{
WORKSHOP REPORT ON ATOMIC BOMB DOSIMETRY - RESIDUAL RADIATION EXPOSURE: RECENT RESEARCH AND SUGGESTIONS FOR FUTURE STUDIES
}

\author{
George D. Kerr,* Stephen D. Egbert, $\uparrow$ Isaf Al-Nabulsi, † Harold L. Beck, $§$ Harry M. Cullings, ${ }^{* *}$ \\ Satoru Endo, $\dagger \dagger$ Masaharu Hoshi, $+\uparrow$ Tetsuji Imanaka, $\S \S$ Dean C. Kaul,*** Satoshi Maruyama, $\dagger \dagger \dagger$

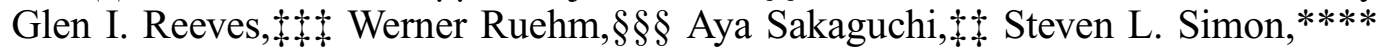 \\ Gregory D. Spriggs, $\dagger+\dagger \dagger$ Daniel O. Stram, + t+t Tetsuji Tonda, $+\$$ Joseph F. Weiss, $\$$ \\ Ronald L. Weitz, $\S \S \S$ and Robert W. Young*****
}

\begin{abstract}
There is a need for accurate dosimetry for studies of health effects in the Japanese atomic bomb survivors because of the important role that these studies play in worldwide radiation protection standards. International experts have developed dosimetry systems, such as the Dosimetry System 2002 (DS02), which assess the initial radiation exposure to gamma rays and neutrons but only briefly consider the possibility of some minimal contribution to the total body dose by residual radiation exposure. In recognition of the need for an up-to-date review of the topic of residual radiation exposure in Hiroshima and $\mathrm{Na}$ gasaki, recently reported studies were reviewed at a technical session at the 57th Annual Meeting of the Health Physics Society in Sacramento, California, 22-26 July 2012. A one-day workshop was also held to provide time for detailed discussion of these newer studies and to evaluate their potential use in clarifying the residual radiation exposures to the atomic-bomb survivors at
\end{abstract}

*Kerr Consulting, Knoxville, TN and Oak Ridge Associated Universities; $†$ Science Applications International Corporation (SAIC), San Diego, CA; $\$$ U.S. Department of Energy, Washington, DC; §U.S. Department of Energy (retired), New York, NY; **Radiation Effects Research Foundation, Hiroshima, Japan; ††Prefectural University of Hiroshima, Japan; +tHiroshima University, Japan; $\S \S$ Koto University, Japan; ***SAIC (retired), Park City, UT; $\dagger \dagger \dagger$ Ministry of Health, Labour and Welfare, Tokyo, Japan; $+\$$ Applied Research Associates, Arlington, VA; $\S \S H e l m h o l t z$ Zentrum Muenchen, German Research Center for Environmental Health, Neuherberg, Germany; ****National Cancer Institute, National Institutes of Health, Bethesda, MD; $\dagger \dagger \dagger$ Lawrence Livermore National Laboratory, Livermore, CA; +++ Hniversity of Southern California, Los Angeles, CA; $\S \S \S \S$ SAIC, Albuquerque, NM; *****Defense Nuclear Agency (retired), Winter Park, FL.

The authors declare no conflicts of interest.

Supplemental digital content is available for this article. Direct URL citations appear in the printed text and are provided in the HTML and PDF versions of this article on the journal's Web site www.healthphysics.com.

For correspondence contact: George D. Kerr, Oak Ridge Associated Universities, P.O. Box 117, Oak Ridge, TN 37831-0117, or email at George.Kerr@orau.org.
(Manuscript accepted 11 February 2013)
0017-9078/13/0
Copyright (C) 2013 Health Physics Society

DOI: 10.1097/HP.0b013e31828ca73a
Hiroshima and Nagasaki. Suggestions for possible future studies are also included in this workshop report.

Health Phys. 105(2):140-149; 2013

Key words: atomic bomb; atomic bomb survivors; fallout; radiation effects

\section{INTRODUCTION}

THE MOST recent assessment of the ionizing radiation dose to survivors at Hiroshima and Nagasaki due to the initial gamma ray and neutron radiation that emanated from the 1945 detonations of atomic weapons in those cities is designated as the Dosimetry System 2002 or simply DS02 (Young and Kerr 2005; Cullings et al. 2006). This reassessment of the initial radiation exposures to the atomic bomb survivors was undertaken to address the potential for a serious discrepancy between calculated and measured values for neutron activation at Hiroshima, causing a lack of confidence in the previous DS86 dosimetry system that had also been developed for the Radiation Effects Research Foundation (RERF) (Roesch 1987; National Research Council 2001). The possibility of some minimal contribution to the total whole body doses by residual radiation exposure was considered briefly in the DS86 and DS02 documents. Due to both time and funding limitations, it was not possible to review in detail the residual radiation exposures from neutron activation products and fission product fallout in the environment as a part of the DS02 study, and it was expected that an up-to-date review would require ongoing efforts by numerous research groups (Egbert and Kerr 2012). Thus, a special half-day technical session and a fullday workshop were held on residual radiation exposures to the atomic bomb survivors at Hiroshima and Nagasaki during the 57th Annual Meeting of the Health Physics 
Society in Sacramento, California, 22-26 July 2012. The primary purpose of the half-day technical session was to review results of recently reported studies on residual radiation in both the United States and Japan (Aoyama and Oochi 2011; Egbert and Kerr 2012), while the purpose of the one-day workshop was to provide time for detailed discussions of these newer studies and to evaluate their potential use in clarifying residual radiation exposures to the atomic-bomb survivors at Hiroshima and Nagasaki. Organizers of the technical session and workshop were Joseph F. Weiss and Isaf Al-Nabulsi of the U.S. Department of Energy; co-chairs for the technical session were Harry M. Cullings and Tetsuji Imanaka; and co-chairs for the workshop were George D. Kerr and Stephen D. Egbert.

\section{TECHNICAL SESSION ON RESIDUAL RADIATION EXPOSURE AT HIROSHIMA AND NAGASAKI-SUMMARY}

This section of the report provides a brief summary of the presentations by the responsible authors at the technical session held during the morning of 24 July 2012. A detailed discussion of the "black rain" at Hiroshima mentioned in several of these presentations can be found in Chapter 6 of the report by Ishikawa and Swain (1981) and the City of Hiroshima report by Aoyama and Oochi (2011). The term "black rain" specifies the color of the rain that fell in some sections of Hiroshima, but it does not necessarily correspond to the presence of fission-product fallout. In the following discussions, the ionizing radiation doses from gamma rays or beta particles may be referred to simply as the gamma dose or beta dose, respectively.

\section{Importance of atomic bomb survivors data (J.D. Boice, Jr.)}

The studies of the Japanese atomic bomb survivors form the foundation of radiation risk estimates used in setting radiation protection guidelines and establishing compensation schemes. Initially, research concerning radiation effects in survivors concentrated on genetic effects, but little evidence emerged on heritable effects. However, strong associations with the occurrence of cataracts of the eye lens, leukemia, and solid tissue cancers were subsequently noted in the exposed survivor population. Until recently, it was considered that initial gamma and neutron exposures were far more important than residual radiation from fission or activation products. Because of the important role that atomic bomb survivor risks play in radiation protection schemes worldwide, there is a need for accurate dosimetry for the survivors, including their doses from residual radiation. The focus of this session and the related workshop the following day was concentrated on a reexamination of this issue.

\section{Residual radiation exposure at Hiroshima and Nagasaki-A historical perspective (G.D. Kerr)}

The altitudes of the explosions at Hiroshima and Nagasaki (600 m and $503 \mathrm{~m}$, respectively) resulted in a fireball that did not touch the ground surface, thereby generating only minimal fission product fallout in both cities. Fallout from Hiroshima was, nevertheless, tracked to the United Sates and as far inland as Lake Michigan (Blair et al 1945; Strohl 2011). There were also areas such as KoiTakasu to the west of Hiroshima and Nishiyama to the east of Nagasaki where survivors were exposed to fission product fallout. In general, internal doses were small compared to the external gamma-ray doses from the fission product fallout. Gamma-ray doses from neutron activation of certain chemical elements in the soil of the hypocenter areas in both cities were also found to be negligible compared to the initial radiation doses due to gamma rays and neutrons from the exploding weapons.

\section{Radiation dosimetry study in Hiroshima (M. Hoshi)}

The subject of this paper was the search for residual radiation, particularly in the areas of "black rain." Starting shortly after the detonation at Hiroshima, rain began that lasted up to $3 \mathrm{~h}$. The rain extended out to $30 \mathrm{~km}$ from the hypocenter, and in some areas was heavy. Soot, burned paper, and other materials mixed with bomb debris were washed out of the sky, causing black streaks that contained fission products on the wall of a house (Fujikawa et al 2003; Shizuma et al 2012). Fission products and radioactive bomb materials have also been found throughout Hiroshima, but only extremely small amounts can be attributed to the Hiroshima bomb when global fallout from later weapon tests is taken into account. Various other continuing Japanese studies were discussed in other presentations during this technical session. For example, higher cancer risks have been noted in some areas northwest of Hiroshima that were in the "black-rain" region that could lead to a reconsideration of the risk factors based on DS02 (Tonda et al 2012).

\section{Review of residual radiation surveys during the early} stage after the Hiroshima bombing (T. Imanaka)

Several Japanese teams conducted radiation surveys only a few days after the bombings. U.S. teams also surveyed the cities several weeks after the detonations. Most of the surveys in Hiroshima were in the delta area of the city that includes the hypocenter and Koi-Takasu area. However, the surveys did not initially include the mountainous "black-rain" area that was located northwest of the city. A few early entrants into the hypocenter area apparently had biological effects similar to those manifested in survivors exposed to large doses. These effects cannot be explained by their exposures to gamma ray radiation from neutron activation of the soil (Imanaka et al. 2011). 
Fallout deposition in Hiroshima where gamma-ray thermoluminescence measurements exceed the dosimetry system (DS02) doses (S.D. Egbert)

Measurements of thermoluminescence (TL) of tiles in several areas in Hiroshima indicated measured doses larger by up to 0.8 Gy than could be explained by exposure to initial radiation from the detonation. This excess dose was particularly noticeable in four areas around the city (Egbert and Kerr 2012). It was suggested that this was due to some sources of radiation that are unique to the Hiroshima detonation. Discrepancies between measured and calculated doses were only discernible by this method at distances more than $1 \mathrm{~km}$ from the hypocenter. Some of the excess readings were in the areas affected by black rain, but several were in other areas. More TL measurements are needed to confirm and determine the extent of this newly identified pattern of excess measured gammaray dose that has not been previously reported.

\section{Some nuclear fallout characteristics of the Hiroshima detonation (G.D. Spriggs)}

Several nuclear tests at Nevada had similar characteristics (e.g., yield and scaled height of burst) as the Hiroshima and Nagasaki bombs. In those tests, no cratering of the soil beneath the detonations was observed. Soil was picked up into the blast stem, though apparently too late to be sucked into the fireball. The absence of soil particles in the fireball would cause the bomb debris to solidify into submicron particles. These very small submicron particles created within the fireball would not fall to the ground in either Hiroshima or Nagasaki unless they were carried down with rain, since gravitational settling for such small particles is very slow. The speaker indicated any local fallout that may have occurred in Hiroshima or Nagasaki was due primarily to neutron-activated soil or building debris lofted by the low pressure trough behind the reflected blast wave that was produced when the primary blast wave from the detonation bounced off the ground in the hypocenter area. Based on experimental data from the Nevada Test Site (currently known as the Nevada National Security Site), it was estimated that approximately $1 \%$ of the total neutron-activated soil would be lofted by a nuclear explosion having a scaled height-of-burst similar to that of the Hiroshima bomb. This would amount to the lofting of approximately $10^{17} \mathrm{~Bq}$ of neutron-activated radionuclides at Hiroshima. Because the mean particle size of most topsoil is of the order of several hundred microns, the lofted neutron-activated radionuclides would represent a significant local fallout source term. A video of a nuclear weapon test in Nevada at a similar scaled height clearly demonstrates the large amount of dust and soil that can be lofted at a scaled height of burst similar to the Hiroshima detonation. See supplemental digital content, http://links.lww.com/HP/A14. The phenomenon
August 2013, Volume 105, Number 2

of horizontal scouring or sweeping of a ground surface by the blast wave from a nuclear detonation was discussed briefly.

Activation analysis for soils of Hiroshima City and estimation of gamma-ray dose due to neutron-induced activated soil by the Hiroshima atom bomb (S. Endo)

In the first few minutes post-detonation, the gamma dose rate from neutron-induced radioactivity is dominated by ${ }^{28} \mathrm{Al}$, in the first few days by ${ }^{24} \mathrm{Na}$, and after a few weeks by ${ }^{46} \mathrm{Sc}$. These elements plus ${ }^{56} \mathrm{Mn}$ are responsible for the irradiation of early entrants into a detonation area. Soil concentrations of these elements (in particular sodium) differ between Hiroshima and Nagasaki. The cumulative skin dose due to gamma rays from activated soil for continuous exposure during $7 \mathrm{~d}$ at the Hiroshima hypocenter was calculated to be approximately $0.8 \mathrm{~Gy}$.

\section{Survey of beta-dose assessment methodologies applicable to Hiroshima (R.L. Weitz)}

This presentation addressed methods of assessing the beta particle dose to skin in a nuclear environment. The beta-to-gamma dose ratio for skin exposed at a height of $1 \mathrm{~m}$ above a horizontally large (e.g., kilometer-sized), uniform layer of ground-deposited fission products is on the order of 10 for the first 100 days after detonation (Barss and Weitz 2006). This ratio increases significantly for finitesized sources with radii less than about $100 \mathrm{~m}$. The beta-togamma dose ratios for skin at $1 \mathrm{~m}$ above neutron-activated Hiroshima-type soil are in the range of $0.05-0.15$ for most times of interest. The dominant radionuclide in neutronactivated soil from $10-100 \mathrm{~h}$ post-detonation is ${ }^{24} \mathrm{Na}$, with relatively minor contributions from ${ }^{56} \mathrm{Mn}$ and ${ }^{42} \mathrm{~K}$. Beta and gamma doses from dermal contact as a function of time after detonation and skin thickness from both fission-product fallout and neutron-activated soil were also discussed.

\section{Preliminary results of ${ }^{236} \mathrm{U},{ }^{239} \mathrm{Pu},{ }^{240} \mathrm{Pu}$, and ${ }^{137} \mathrm{Cs}$ measurements in samples related to "Black Rain" after the Hiroshima atomic bomb (A. Sakaguchi)} Production of ${ }^{236} \mathrm{U},{ }^{239} \mathrm{Pu},{ }^{240} \mathrm{Pu}$, and ${ }^{137} \mathrm{Cs}$ from the Hiroshima bombing and Cold War weapon tests were discussed. Measurements made by Accelerator Mass Spectrometry (AMS) and Thermal Ionization Mass Spectrometry (TIMS) were described and compared. The AMS measurements show a uniform spatial pattern over Hiroshima (Sakaguchi et al. 2010); however, the TIMS measurements indicate higher values in the north and west direction from the hypocenter. Samples taken from soil beneath houses built in the "black-rain" areas after the bombing show less interference from deposition of global fallout produced during weapon testing programs. The measurements from the underfloor samples, found far to the west or north of Hiroshima, do not have the same spatial pattern as the Hiroshima "blackrain," possibly due to contamination from Cold War weapon 
tests or the Nagasaki explosion. Further analyses are needed to identify the radionuclide composition originating from fallout in "black rain."

\section{Reconstruction of spatial-time distribution of "Black Rain" in Hiroshima based on statistical analysis of the Survey of Atomic Bomb Survivors \\ (M. Ohtaki, T. Tonda)}

This work looked at heavy "black-rain" areas such as Uda's (Aoyama and Oochi 2011), where survivors receive government support. A description of the rainfall post-detonation was constructed based on questionnaires distributed in 2008. The questions involved location, start and end times, intensity, color of rain, and presence of flying materials. The estimated rainy area using information from the questionnaires is several times larger than Uda's heavy "black-rain" area. Thus, many more survivors may have been exposed to "black rain" based on the information obtained from the recent questionnaires.

\section{Investigation of circular asymmetry of geographical distribution of mortality risk in Hiroshima atomic bomb survivors ( $T$. Tonda)}

The speaker reviewed the dependency of mortality risk at Hiroshima using the so-called Hiroshima University Registry at the Research Institute for Radiation Biology and Medicine (RIRBM) (Hoshi et al. 1996) and adjusting the risk at Hiroshima to account for background factors (gender and age at time of exposure), radiation dose, and distance from the hypocenter. In this work, a spatial variation was identified that could not be attributed to background factors or initial radiation dose from the bomb detonation because the relative risk was found to increase close to the hypocenter and toward the northwest. Correlating this excess relative risk with radiation dose would imply that there was an increase in the radiation dose to survivors around the hypocenter and in the area northwest of the hypocenter, where the "black rain" fell. The speaker thought that the DS02 system should be updated.

Doses received by atomic bomb survivors in the Life Span Study cohort from known residual radiation sources in Hiroshima and Nagasaki (H.M. Cullings)

There are two well documented areas of fissionproduct fallout: the Koi-Takasu area near Hiroshima and the Nishiyama area in Nagasaki. There was much less gammaray dose from neutron activation of the soil at Nagasaki than at Hiroshima, and recent calculations of the radiation exposure to early entrants into these areas (evacuees and others) indicate that these external doses from gamma rays were only around 3-24 mGy. Other recent calculations have also confirmed that internal exposure from inhalation or ingestion of activated soil would have resulted in effective internal doses of less than $5 \mathrm{mSv}$. The average estimated dose from fallout gamma rays in the Koi-Takasu area was around $12.7 \mathrm{mGy}$; by contrast, the average dose from initial radiation was $220 \mathrm{mGy}$. Doses from residual radiation sources would, therefore, be much less than DS02 calculated doses. There is some uncertainty as to how much radiation might have come from short-lived fallout debris such as radioactive iodines. Also, estimates for soil activation exposure to early entrants and evacuees are a little uncertain. Most people within $1 \mathrm{~km}$ of the hypocenter had to evacuate due to the fires and re-enter later, thereby reducing their exposure to residual radiation. The total population dose (person-Gy) from external exposure to gamma rays from fallout was estimated to be less than $1 \%$ of the initial population radiation dose from gamma rays at Hiroshima and less than 5\% at Nagasaki.

\section{WORKSHOP ON RESIDUAL RADIATION EXPOSURES AT HIROSHIMA AND NAGASAKI-SUMMARY}

This section summarizes the discussions during the full-day workshop on 25 July 2012 that were focused on new approaches for estimating potential exposures to

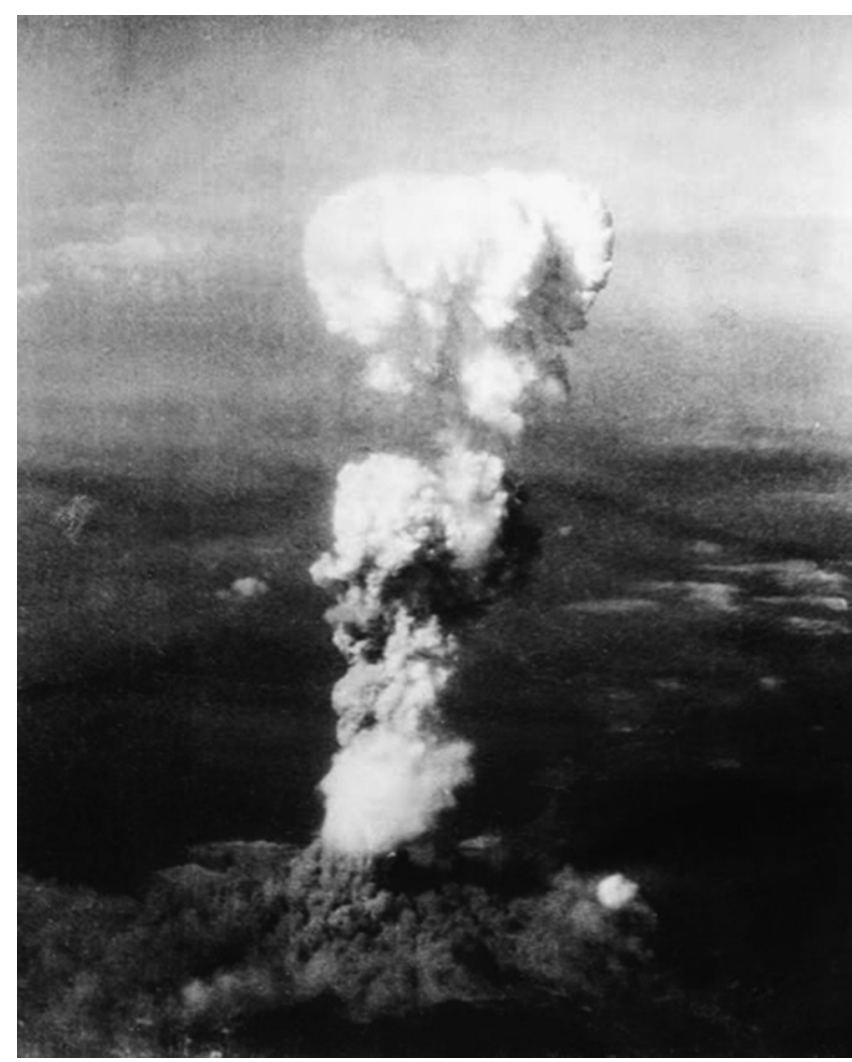

Fig. 1. Photograph of the developing mushroom cloud at Hiroshima. At the time of the photograph, the cap of the mushroom cloud had reached approximately 20,000 feet $(6 \mathrm{~km})$ and the pedestal (or dust base) of the mushroom cloud had spread over a diameter of more than 10,000 feet $(3 \mathrm{~km})$ (National Archives). 


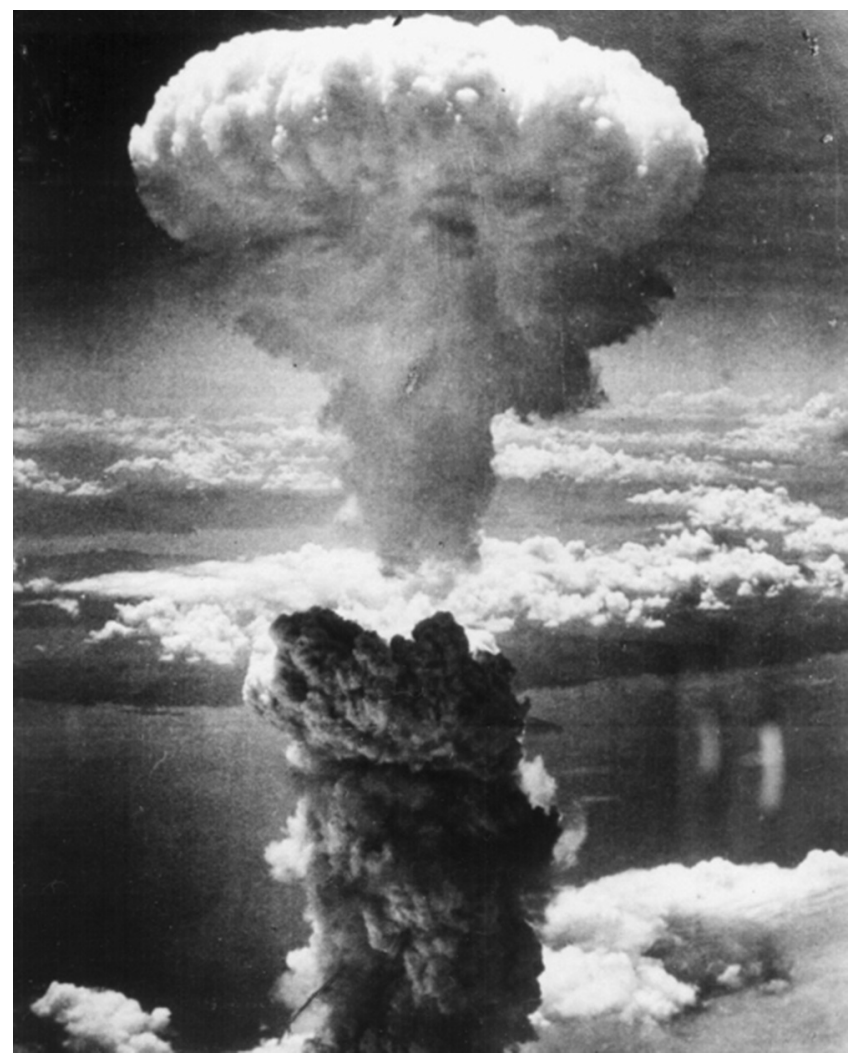

Fig. 2. Photograph of stem and cap of the Nagasaki mushroom at its maximum height of approximately 30,000 feet $(9 \mathrm{~km})$. The separation between the cap plus bomb debris stem and the dust stem containing lofted neutron-activated soil and building debris are clearly visible (National Archives).

residual radiation at Hiroshima and Nagasaki. The agenda for the workshop also called for a discussion of biological effects such as epilation, bleeding, vomiting, cataracts, and cancer, including their asymmetry about the hypocenter area that might suggest exposure to residual radiation (Sawada 2011; Tonda et al. 2012). Recent Japanese studies have essentially ruled out fission products as a significant source of fallout exposure to survivors in Hiroshima, except in a few locations between 2.0 and $3.5 \mathrm{~km}$ to the west of the hypocenter (Aoyama and Oochi 2011). Thus, the most likely source of a significant residual radiation exposure to survivors near the hypocenter areas at Hiroshima and Nagasaki appears to result from (1) the lofting of neutron-activated radionuclides from soil and other environmental materials into the atmosphere by the ground shock from the blast wave of the explosion (see Figs. 1 and 2) and (2) the horizontal scouring and sweeping of ground and river water by the blast wave, which moved some neutron-activated materials to larger ground distances (Egbert and Kerr 2012).

Fallout was studied extensively during many U.S. nuclear weapons tests at the Nevada Test Site [see Glasstone
August 2013, Volume 105, Number 2

and Dolan (1977) for a summary]. The amount and type of fallout was found to depend primarily on the energy yield of a weapon (Y) and its height of burst (HOB). A falloutfree HOB, as its name implies, is sufficiently high so that the fireball produced by the nuclear weapon does not touch the ground surface, and in the absence of rain, the explosion generates little local fallout from fission-products. The fallout-free HOB threshold for fission products in meters is equal to $55 \times \mathrm{Y}^{0.4}$, where units of $\mathrm{Y}$ are in kilotons (kt), 1 kiloton being the energy produced when 1,000 tons of highly explosive TNT is detonated (Glasstone and Dolan 1977). For the Hiroshima explosion with an energy yield of $16 \mathrm{kt}$, the fallout-free HOB threshold for fission products is approximately $167 \mathrm{~m}$; for the Nagasaki explosion with an energy yield of $21 \mathrm{kt}$, the fallout-free HOB threshold for fission products is approximately $185 \mathrm{~m}$. These fallout-free HOB thresholds for fission products are significantly less than the currently recommended HOBs of $600 \mathrm{~m}$ and $503 \mathrm{~m}$ for the Hiroshima and Nagasaki explosions, respectively (Young and Kerr 2005). There was, of course, some fission product fallout associated with the black rain that fell in the Koi-Takasu area, located several kilometers to the west of the hypocenter at Hiroshima, and the Nishiyama area located several kilometers to the east of the hypocenter at Nagasaki. However, only small amounts of fission products were found during early surveys in the hypocenter areas of the two cities, and a retrospective analysis of ${ }^{137} \mathrm{Cs}$ in soil confirmed that little or no fission products fell in the Hiroshima hypocenter (Aoyama and Oochi 2011). The fission-product cloud of the Hiroshima explosion was tracked by aircraft to the west coast of the United States and as far inland as Lake Michigan (Blair et al. 1945; Strohl 2011).

It is possible to make other general statements about the source and amount of fallout from an explosion by referring to a weapon's shock-scaled height of burst (SHOB), which is defined as $\mathrm{SHOB}=\mathrm{HOB} \times \mathrm{Y}^{-1 / 3}$ by G.D. Spriggs (Egbert and Kerr 2012). The SHOB for an explosion is used to assign it to one of several regimes that describe the potential for mixing of (1) the cap and the debris stem containing the fission products and actinides (e.g., uranium and plutonium) plus neutron-activated weapon materials and (2) the dust stem from the explosion containing neutron-activated radionuclides from soil and other materials on the ground. The SHOBs are $238 \mathrm{~m}$ and $182 \mathrm{~m}$ for the Hiroshima and Nagasaki explosions, respectively. These SHOBs for the Hiroshima and Nagasaki weapons place them in Spriggs' third regime, which has "no appreciable local fallout" of fission products. For SHOBs in Spriggs' third regime, the dust stem is drawn into the bomb debris stem above the HOB of the explosion but not into the cap of the mushroom cloud containing the fission-product radionuclides at times early 
enough to affect condensation of bomb debris into very small particles. The caps of the mushroom clouds at Hiroshima and Nagasaki rose to an altitude of about 30,000 feet $(9 \mathrm{~km})$ before they reached thermal equilibrium with the surrounding atmosphere. Once this happened, the dust stem collapsed and the larger sized particles in the dust stem fell back quickly into the area around the hypocenter of the explosion. Smaller sized particles in the dust stem remained aloft for longer periods of time and were scattered over much larger areas around the explosions (Fields et al. 1989). The particle size distribution is important in predicting the behavior of the particles in the dust stem during its collapse, and measurements of the particle size distribution for a soil of interest are discussed in a recent report by Spriggs and Ray-Maitra (2007).

Neutron-activated radionuclides decay by the emission of both gamma rays and beta particles. Significant differences were found during early surveys of the in-air dose rates from gamma rays in the hypocenter areas of Hiroshima and Nagasaki (Roesch 1987). These differences were due in part to the intensities of the neutron fluence incident on the ground in the hypocenter areas of the two cities (Young and Kerr 2005; Egbert et al. 2007) and the compositions of the soil in the hypocenters of the two cities (Hashizume et al. 1969; Young and Kerr 2005). The early surveys usually measured only the in-air dose rates from gamma rays. Compared to the measured or calculated gamma-ray dose rate in air at $1 \mathrm{~m}$ above undisturbed ground, the beta-ray dose rate from neutron-activated radionuclides is only about one-tenth of that from the gamma rays because soil and air attenuate the short-range beta radiation much more effectively than the gamma radiation (Barss and Weitz 2006). However, the skin of some survivors may have been contaminated by neutron-activated radionuclides from (1) the lofting of soil and other environmental materials into the atmosphere by the blast wave from the explosion; (2) the scouring and sweeping of the ground and river water by the blast wave, which moved some neutron-activated radionuclides to larger ground distances; and (3) transfer of contamination to the body from the handling of contaminated objects.

The most important beta-particle emitters produced by neutron activation of soil are ${ }^{24} \mathrm{Na}\left(\mathrm{t}_{1 / 2}=15 \mathrm{~h}\right)$, ${ }^{31} \mathrm{Si}\left(\mathrm{t}_{1 / 2}=2.6 \mathrm{~h}\right),{ }^{56} \mathrm{Mn}\left(\mathrm{t}_{1 / 2}=2.6 \mathrm{~h}\right)$, and ${ }^{38} \mathrm{Cl}\left(\mathrm{t}_{1 / 2}=37 \mathrm{~m}\right)$ (Glasstone and Dolan 1977). Due to the relatively short half-lives of these beta-emitting radionuclides, the radiation dose to the skin from beta particles would be delivered over a very brief period of about $2 \mathrm{~d}$, and the contribution to epilation from beta radiation would be indistinguishable from that due to the much larger whole body radiation doses to survivors at distances much nearer to the detonations. Because the range of the beta particles in tissue is only a few millimeters, the only organs at risk from external irradiation by beta particles from neutron activated radionuclides deposited on the surface of the body would be the skin and the lens of the eye. If the neutron activated radionuclides are deposited on clothing, the risk to the skin would be reduced since, unlike gamma rays, beta particles are absorbed significantly by clothing over the skin (McNaught 1983). The complexities involved in determining radiation doses to skin from fallout have been discussed by Apostoaei and Kocher (2010).

\section{WORKSHOP ON RESIDUAL RADIATION EXPOSURES AT HIROSHIMA AND NAGASAKI-RECOMMENDED FUTURE STUDIES}

During the workshop, there were discussions of work that has been ongoing for several years or that has been considered. Most recent studies have been funded by the City of Hiroshima and Japanese universities and may be arriving successfully at their conclusions in the near future. These studies have included descriptions of the fireball and of cloud formation, surveys of radioisotope deposition by radiochemistry and intensity measurements, meteorology and black rain, firestorm, beta dosimetry, and so forth. Other workshop discussions led to a crossfertilization of ideas resulting in several recommendations for possible new investigations, measurements, calculations, or analysis. Additionally, it was thought that many previously examined ideas concerning residual radiation dose should be reanalyzed or expanded with the new perspective provided by the workshop discussions.

A list of ideas for new approaches and new studies aimed at clarifying potential exposures to residual radiation that were mentioned or discussed during the workshop are listed in the Appendix to this report. It was clear that there could not be a definitive and reliable estimate of the amount of residual dose to individual Japanese survivors without several questions being answered. These questions include: (1) sources of residual radioactivity, (2) radioisotopes present and associated energy and particle emissions; (3) pathways for radioisotopes to co-locate with survivors; (4) methods to physically determine the level of surface contamination; (5) duration of survivor exposures; (6) mechanisms for the delivery of organ doses from external exposure due to gamma rays or beta particles and organ doses from internal exposure due to inhaled or ingested radioisotopes; (7) spatial analyses of biological effects, specifically noting asymmetries and anomalies in excess of the DS02 dose estimates for the initial radiations from the bombs; and (8) comparing and understanding differences between residual radiation exposures at Hiroshima and Nagasaki. As these questions are answered, it will also be important to estimate the uncertainties on survivor 
residual dose estimates and whether including them in the dosimetry system is justified or needed. It is too soon to know if it will be possible to quantify a survivor's residual dose and whether accounting for this dose will affect risk factors or estimated survivor dose uncertainties that currently exceed those derived from the DS02 dosimetry.

During the workshop discussion, several of these ideas were prioritized. The first priority included a few studies that appear simple with small associated costs. An example is to measure particle size distributions of soil and salinity of the brackish rivers (M.IIIa, M.IIIb as identified in the Appendix). A second priority is to physically determine the level of surface contamination. This would require that ceramic samples for TL measurements need to be located and analyzed (M.VIa, M.VIb). It was stated in the workshop that it has been difficult to locate any new ceramic samples for many years, but perhaps by focusing on neighborhoods of potential residual radiation importance or reviewing previously collected samples as candidates for beta dose measurements, it would be a worthwhile effort (M.VIc). The priority of this is based on the notion that without a physical determination of dose, it may be impossible to assign a residual dose to survivors. As a third priority for study, it was proposed that neutron-activated soil and building debris may be an important source of residual radiation exposure to survivors at both Hiroshima and Nagasaki (M.III, C.I). Several of the tasks, which are needed to establish reasonable estimates or maxima for survivor residual doses, could begin by reconstructing the ground activation and movement by ground sweep and stem formation (M.IV, C.II, C.III, C.IV). These parameters have been estimated for nominal weapon test conditions. Quantification of the unique Hiroshima ground and meteorology conditions should be used to modify the nominal results. Meteorological conditions, which have been thought to be nearly impossible to obtain, may be achievable with meteorological reconstruction from historic databases and with photographic reconstruction based on the movements of the nearly instantaneously created pedestal, stem, and cap, and then later in the morning of the detonation, by movements of continuously released smoke rising from the firestorm.

Finally, there have been some studies suggesting asymmetries and anomalies of survivors' biological effects, which cannot be accounted for by the DS02 dosimetry system. There are several types of biological endpoints, which could be spatially analyzed in order to identify spatial patterns, either to suggest possible unknown fallout hotspots or to lend support to the existence of particular areas of deposited bomb debris and activated ground created via proposed pathways. It should be noted that some of these biological endpoints are more specific for exposure to ionizing radiation than others and that all of them occur at frequencies influenced by other covariates beside ionizing radiation. Spatial analyses must use proper spatial and epidemiological methods and must be interpreted with caution to avoid misleading attribution of putative spatial patterns to ionizing radiation if they may have been caused by other risk factors or may have arisen by chance alone. It was also recommended that the RIRBM and RERF databases be used to evaluate the evidence for biological effects not explained by the existing DS02 dosimetry (M.VII, A.Ia, A.Ib). For example, chromosome aberrations were thought to be a good biological indicator of gamma-ray exposure, while epilation in persons with negligible exposure to the initial gamma radiation from the bombs was thought to be an indicator of possible exposure to beta particles from residual radiation. Creating a residual dosimetry model and related database for both beta and gamma exposure can provide a way to estimate the correlation between these various biological outcomes (C.VI, A.Ic, A.Id.).

\section{WORKSHOP ON RESIDUAL RADIATION EXPOSURES AT HIROSHIMA AND NAGASAKI-CONCLUSIONS}

Both Japanese and American investigators acknowledge the existence of some measurement data related to the Hiroshima and Nagasaki detonations that appears anomalous when compared to the symmetry of estimated dose around the hypocenters by the DS02 calculations. A possible explanation of these anomalies is residual radiation exposure that was varied and spatially inhomogeneous. The origins of the exposure could have been contaminated rain (e.g., the black rain) or the scouring and sweeping action of the blast wave on neutron-activated soil. While there is little quantitative evidence of these specific phenomena at this time, the Workshop developed a number of ideas for further study that might lead to a better understanding of residual dose. That understanding is essential because of the importance of atomic bomb dosimetry to the field of radiation protection. It should be noted, however, that the individual authors of this workshop report may place differing weights on the specific suggestions for future studies related to residual radiation at Hiroshima and Nagasaki.

Acknowledgments - We wish to thank David Landguth, Oak Ridge National Laboratory, for his organizational expertise that resulted in a highly successful workshop. The help and advice of the Health Physics Society meeting organizers and the staff of Burk and Associates are greatly appreciated. We would also like to thank John Boice for his excellent presentation at the start of the technical session, although he was not able to participate in the workshop. The participation of George D. Kerr, Steve D. Egbert, Harold L. Beck, Harry M. Cullings, Satoru Endo, Masaharu Hoshi, Tetsuji Imanaka, Dean C. Kaul, Aya Sakaguchi, Gregory D. Springs, Daniel O. Stram, and R. L. Weitz in the workshop was financially supported by the U.S. Department of Energy (DOE). The views of the authors do not necessarily reflect those of the DOE, the U.S. government, or the authors' institutions. 


\section{REFERENCES}

Apostoaei AI, Kocher DC. Radiation doses to skin from dermal contamination. Fort Belvoir, VA: Defense Threat Reduction Agency; DTRA-TR-09-16; 2010. Available at www. dtra.mil/SearchResult.aspx?strSearch=dtra-tr-09-16. Accessed 28 November 2012.

Aoyama M, Oochi Y. Revisit the Hiroshima A-bomb with a database-latest scientific view on local fallout and black rain. Hiroshima: The City of Hiroshima; 2011. Available at http://city.youth-service.com/0300database.html. Accessed 28 November 2012.

Barss NM, Weitz RL. Reconstruction of external dose from beta radiation sources of nuclear origin. Health Phys 91: 379-389; 2006.

Blair J, Frish D, Katcoff S. Detection of nuclear-explosion dust in the atmosphere. Los Alamos, NM: Los Alamos Scientific Laboratory; LA-418; 1945. Available at http://www. fas.org/sgp/othergov/doe/lanl/docs1/00423503.pdf. Accessed 28 November 2012.

Cullings HM, Fujita S, Funamoto S, Grant EJ, Kerr GD, Preston DL. Dose estimation for atomic bomb survivors: its evolution and present status. Radiat Res 166:219-254; 2006.

Egbert SD, Kerr GD, Cullings HM. DS02 fluence spectra for neutrons and gamma rays at Hiroshima and Nagasaki with fluence-to-kerma coefficients and transmission factors for sample measurements. Radiat Environ Biophys 46:311-325; 2007.

Egbert SD, Kerr GD. Gamma-ray thermoluminescence measurements: a record of fallout deposition in Hiroshima? Radiat Environ Biophys 51:113-131; 2012.

Fields DE, Cole LL, Summers S, Yalcintas MG, Vaughan GL. Generation of aerosols by urban fire storm. Aerosol Sci Technol 10:28-36; 1989. Available at www.tandfonline. com/doi/pdf/10.1080/02786828908959218. Accessed 28 November 2102.

Fujikawa Y, Shizuma K, Endo S, Fukui M. Anomalous ${ }^{235} \mathrm{U} /$ ${ }^{238} \mathrm{U}$ ratios and metal elements detected in the black rain from the Hiroshima A-bomb. Health Phys 84:155-162; 2003.

Glasstone S, Dolan PJ. The effects of nuclear weapons. Washington, DC: U.S. Government Printing Office; 1977. Available at www.atomicarchive.com/Docs/Effects/index.shtml. Accessed 28 November 2012.

Hashizume T, Maruyama T, Kumamoto Y, Kato Y, Kawamura S. Estimation of gamma-ray dose from neutron-induced radioactivity in Hiroshima and Nagasaki. Health Phys 17: 761-771; 1969.

Hoshi M, Matsuura M, Hayakawa N, Ito C, Kamada N. Estimation of radiation doses for atomic bomb survivors in the Hiroshima University Registry. Health Phys 70:735-740; 1996.

Imanaka T, Endo S, Kawano N, Tanaka K. Radiation exposure and disease questionnaires of early entrants after the Hiroshima bombing. Radiat Protect Dosim 149:91-96; 2011.

Ishikawa E, Swain DL. Hiroshima and Nagasaki-the physical, medical, and social effects of the atomic bombings. Tokyo: Iwanami Shoten, Publishers; 1981.

McNaught LW. Nuclear weapons and their effects. London: Brassey's Defence Publishers; 1983.

National Research Council. Status of the dosimetry for the Radiation Effects Research Foundation (DS86). Washington, DC: National Academy Press; 2001. Available at www.nap.edu/ catalog.php?record_id=10103. Accessed 28 November 2012.

Roesch WC. U.S.-Japan joint reassessment of atomic bomb dosimetry in Hiroshima and Nagasaki. Hiroshima: Radiation Effects Research Foundation; 1987. Available at http://www. rerf.jp/library/index_e.html. Accessed 28 November 2012.
Sakaguchi A, Kawai K, Steier P, Imanaka T, Hoshi M, Endo S, Zhumadilov, Yamamoto M. Feasibility of using ${ }^{236} \mathrm{U}$ to reconstruct close-in fallout deposition from the Hiroshima atomic bomb. Sci Total Environ 408:5392-5398; 2010.

Sawada S. Estimation of residual nuclear radiation effects on survivors of Hiroshima atomic bomb from incidence of acute radiation disease. Bulletin Social Med 29:1-16; 2011. Available at http://jssm.umin.jp/report/no29-1/29-1-06.pdf. Accessed 28 November 2012.

Shizuma K, Endo S, Fujikawa Y. Isotope ratios of ${ }^{235} U /{ }^{238} U$ and ${ }^{137} \mathrm{Cs} /{ }^{235} \mathrm{U}$ in black rain streaks on plaster wall caused by fallout of the Hiroshima atomic bomb. Health Phys 102: 154-160; 2012.

Spriggs GD, Ray-Maitra A. Particle-size-distribution of Nevada Test Site soils. Livermore, CA: University of California; UCRL-TR-234937; 2007. Available at http://e-reportsext.llnl.gov/pdf/352738.pdf. Accessed 28 November 2012.

Strohl F. Tons of Manhattan Project documents stored near Atlanta. Oak Ridge, TN: Oak Ridge National Laboratory Reporter; No129; p. 3; February 2011. Available at www. ornl.gov/info/reporter/no129/february2011.pdf. Accessed 28 November 2012.

Tonda T, Satoh K, Otani K, Sato Y, Maruyama H, Kawakami H, Tahiro S, Hoshi M, Ohtaki M. Investigation on circular asymmetry of geographical distribution in cancer mortality of Hiroshima atomic bomb survivors based on risk maps: analysis of spatial survival data. Radiat Environ Biophy 51: 133-141; 2012. Available at http://link.springer.com/article/ 10.1007/s00411-012-0402-4. Accessed 28 November 2012.

Young RW, Kerr GD. Reassessment of the atomic bomb radiation dosimetry for Hiroshima and Nagasaki-Dosimetry System 2002. Hiroshima: Radiation Effects Research Foundation; 2005. Available at www.rerf.jp/library/index-e.html. Accessed 28 November 2012.

\section{APPENDIX - COMPREHENSIVE LIST OF SUGGESTED FUTURE STUDIES ON RESIDUAL RADIATION AT HIROSHIMA AND NAGASAKI}

The following list organizes new ideas and approaches for future studies that were mentioned and/or discussed during the workshop. Suggestions as to why some studies are considered to have higher priorities than others are discussed in the main body of the report.

\section{Investigations and measurements (M)}

1. Finish analyses of black rain, drizzle, firestorm, radiation, and radioisotopes surveys.

2. Quantify the ground surface features around hypocenters at time of detonation.

a. Urban topography (open flat areas, urban corridors, hilly terrain); and

b. Location, density, thickness of soil, water, asphalt, vegetation, roof, wall, concrete, and building combustibles.

3. Identify or quantify the hypocenter areas' ground characteristics. 
a. Particle-size-distributions in soil; i.e., collect and analyze 1-L soil samples obtained at surface depths between $0-4 \mathrm{~cm}$ from locations near the hypocenters that have remained undisturbed since 1945;

b. Composition of brackish rivers at time of the explosions (around high tide); and

c. Activated urban materials, including large amounts of clay soil and other materials used in Japanese house construction that are movable by blast, stem formation, or thermal updraft.

4. Quantify the winds and weather near hypocenters, especially at the hour of detonation.

a. Local and regional August 1945 meteorological measurements, historic and reconstructed weather databases, mushroom cloud photographs, eyewitness accounts, and proxy days similar to August 1945 atmosphere conditions; and

b. Wind shear boundaries and time-dependent velocity of pedestal, stem, and cap.

5. Survivor movement and residual shielding scenarios.

a. Identify likely scenarios after detonation, for residual exposure shielding;

b. Identify typical clothing, decontamination, inhalation or ingestion scenarios; and

c. Identify typical paths and times for evacuees and early entrants.

6. Physical dosimetry database of the asymmetry and anomalies unexplained by DS02.

a. Locate, collect, and analyze ceramic TLD samples, particularly at locations with high and low probabilities of residual fallout;

b. Determine age and background dose of ceramic TLD samples; and

c. Measure ceramic TLD dose as a function of depth to ascertain the beta component.

7. Biological dosimetry database of the asymmetry and anomalies unexplained by DS02.

a. Deep organs (chromosome aberration and cancer mortality) less affected by beta particles;

b. Body surfaces (epilation, purpura, gingival bleeding, cataract) affected by beta particles;

c. Include both RIRBM and RERF results to develop a biological dosimetry database; understand, reconcile differences; and

d. Identify and account for confounders; e.g., diagnostic and therapeutic radiation doses

\section{Calculations (C)}

1. Soil, urban materials, and brackish water activation by initial neutron fluence. a. As a function of depth, distance, and surface features in both cities; and

b. Quantify production of radioisotopes within the hypocenter area $(<1.5 \mathrm{~km})$.

2. Blast.

a. Simplified air-over-flat ground blast calculation;

b. Perturbations caused by the urban environment; e.g., structures, dust, channeling;

c. Horizontal dynamic pressures - variability and likelihood of Mach stem formation;

d. Scouring of ground materials;

e. Pedestal, stem, and cap rise - height and size as a function of time; and

f. Identify radioisotopes, amount, particle sizes, and distribution in pedestal, stem, and cap.

3. Settling and deposition of dust and debris particles from pedestal, stem, and cap.

4. Weather, winds, and movement of pedestal, stem, and cap.

a. Time-dependent, three-dimensional wind model near and above hypocenters;

b. Inclusion of a rain model and its perturbation to winds, settling, and deposition; and

c. Transport of pedestal, stem, and cap perturbed by chaos of fireball/firestorm.

5. Survivor movements and shielding factors.

a. Calculate dose based on typical paths and times for evacuees and early entrants;

b. Calculate residual exposure shielding for scenarios after detonation; and

c. Calculate modification factors provided by decontamination of the skin and by various types of clothing, including raincoats, which may provide more protection of the skin than other types of summer clothing.

6. Create a residual dosimetry database from ground surface distributions of radioisotopes.

a. From beta and gamma sources to internal organs or body surfaces;

b. External dose from activated ground remaining in place (thick source);

c. External dose from fission products and activated ground deposition (thin source);

d. External dose from fallout deposited on skin (thin source);

e. Inhalation dose from descending or resuspended fallout; and

f. Ingestion dose from activated or falloutcontaminated soil, water, food, and food soaked or cooked in water. 


\section{Analysis (A)}

1. Spatial analysis.

a. Spatially analyze calculated residual doses for survivors (organ or skin surface);

b. Spatially analyze asymmetries and anomalies of the physical and biological dosimetry using both the RIRBM and RERF databases;

c. Create models for relationships of residual radiation dose to physical and biological dosimetry; and d. Use models to analyze spatial correlation among these with each other.

2. Estimate uncertainty and whether developing a residual radiation dosimetry database for subgroups of survivors is justified.

3. Consider implications for risk factors for all survivor radiation effects if residual dose is quantified and included in a database. A dose and dose rate effectiveness factor (DDREF) should be used for biological effects from any protracted exposures from residual radiation. 